\title{
AN APPROACH TO OPTIMAL CONTROL OF THE COMBUSTION SYSTEM IN A REVERBERATORY FURNACE
}

\author{
HenRy Copete LÓPeZ ${ }^{l}$ \\ SAntiago SÁnchez Acevedo²
}

\section{Resumen:}

En este trabajo se presenta una técnica de control óptima aplicada al control del exceso de aire en el proceso de combustión de un horno reverbero mediante el monitoreo del porcentaje de $\mathrm{O}_{2}$ en la chimenea, el controlador es diseñado basado en un modelo no-lineal estimado con redes neuronales y se emplea para el previo entrenamiento una base de datos conformada por dos conjuntos: uno para entrenamiento y otro para la validación.

\section{Palabras Clave:}

Horno reverbero, combustión, controlador digital, redes neuronales, control óptimo.

\section{Abstract:}

In this work an optimal control technique is applied to control the excess air in the combustion process of a reverberatory furnace by the monitoring of $\mathrm{O}_{2}$ percentage in the stack, the controller is designed based on a nonlinear model estimated by artificial neural networks and a data base is used for the previous training; the data base has two subsets one for training and other to validate the net.

1 M.Sc. Ingeniero Mecánico. Grupo GiTER. Instituto Tecnológico Metropolitano. Docente Investigador. henrycopete@itm.edu.co

2 M.Sc. Ingeniero Electricista. Grupo MiRP. Instituto Tecnológico Metropolitano. Docente Investigador. santiagosanchez@itm.edu.co 


\section{Keywords:}

Reverberatory furnace, combustion, digital control, neural networks, optimal control. 


\section{INTRODUCTION}

The reverberatory furnaces have been used in many industrial activities such as glass and nonferrous materials melting. Most aluminum melters and molten aluminum holding (alloying) furnaces, as well as glass melting tanks and frit smelters are refractory-lined reverberatory furnaces (Trinks, 2004). The energy to process the materials is produced by a heat released for the combustion process in gas burners where air and fuel are combined and burned.

Complete combustion of fuel in these burners requires a volume of air in excess of the theoretical requirement. On the other hand, too much air results in an increased volume of exhaust gas, and consequently the heat loss is increased. If the amount of air is minimized while ensuring that incomplete combustion does not occur is an important requirement for energy conservation (NEDO, 2006). Combustion improvement is indicated by the increase of the combustion efficiency in the combustion process of a furnace.

The efficiency of the combustion process is generally controlled in open loop, by setting the air flow in such a way to guarantee the absence of carbon monoxide $\mathrm{CO}$ in all normal operation conditions. This allows avoiding the cost of additional sensors for monitoring the combustion process, as well as the complexity of additional closed loop controllers; however, it limits the efficiency of the combustion systems.

Miyayama et al. (1991) used a combustion controller for a coal-fired boiler. Santoso et al. (2005) design a fuzzy controller for a boiler and Conte et al. (2006) presents a control scheme in domestic boilers; with a typical PID controller, in their work they did not apply an optimization methodology that warranties an optimal performance.

The objective of this work is to develop an efficient methodology to control the combustion process in aluminum reverberatory furnaces. In order to maintain the optimal combustion conditions: the air/fuel ratio with sufficient quantity of $\mathrm{O}_{2}$ and the minimum 
quantity of CO. A standard combustion analyzer have been used (Bacharach $\mathrm{PCA}^{\circledR} 2$ ) in order to monitoring the $\mathrm{O}_{2}$ and $\mathrm{CO}$ in combustion products; in aluminum furnace for different air flows generated by a variable speed fan and to construct the data base.

In this paper a methodology to model and design the controller for a reverberatory furnace is described. The air flow is the control variable and cannot violate the operations bounds given by the load of the furnace, the system model is obtained from a data set that employs measures of the $\mathrm{O}_{2}$ from a gas analyzer and thus, a neural network is trained to estimate the nonlinear model. A modified second order regulator is trained using evolutionary computation the performance index of the training algorithm is the mean square of the tracking error. In the last section results and conclusions of the designed system are shown.

\section{Combustion system for Reverberatory furnace}

The gas - fired reverb furnace consists simply of three parts: a fireplace at one end, a stack or chimney at the other end and a bed between both on which the aluminum is heated (McKenna, 1998). Heat is supplied in a space between the charge and the roof and transferred by radiation and convection.

A simplified schematic diagram of a gas - fired aluminum reverberatory furnace is illustrated in Figure 1. This system comprises a combustion control unit, flue gas $\mathrm{O}_{2}$ sensor, temperature sensor, automatic damper operating unit. Its features allow controlling the excess air ratio and it is possible over the entire load range, from minimum to maximum load with a fast response. 


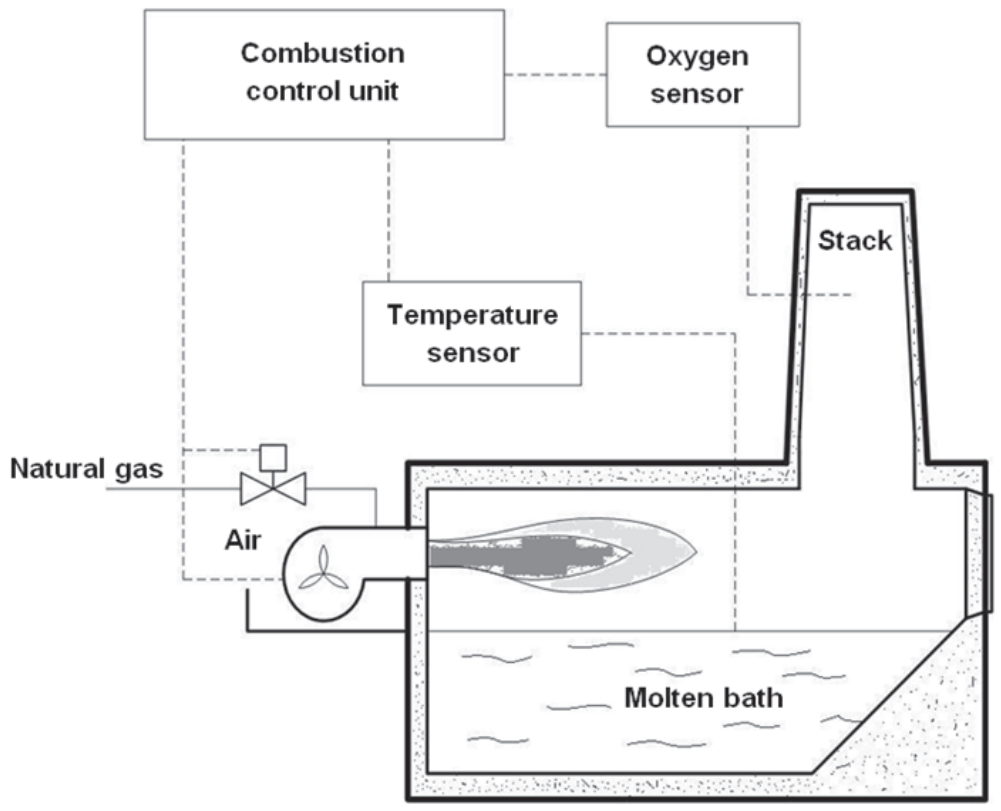

Figure 1. ReVERberatory fuRnace SCHEMATIC DIAGRAM

\subsection{COMBUSTION PROCESS}

Combustion is a specific group of chemical reactions where a fuel and oxygen burn together at sufficiently high temperature to evolve heat and combustion products. The stoichiometric combustion process of gaseous hydrocarbons could be expressed:

$\left.\mathrm{C}_{x} \mathrm{H}_{y}+\left(x+\frac{y}{4}\right) \mathrm{O}_{2}+3,76\left(x+\frac{y}{4}\right) N_{2} \rightarrow x \mathrm{CO}_{2}+\frac{y}{2} \mathrm{H}_{2} \mathrm{O}+3,76\left(x+\frac{y}{4}\right) N_{2}\right\}$ Heat

Natural gas is a gas consisting primarily of methane $\mathrm{CH}_{4}$. The chemical reaction for methane combustion with normal air is $\mathrm{CH}_{4}+2 \mathrm{O}_{2}+7,52 \mathrm{~N}_{2} \rightarrow \mathrm{CO}_{2}+2 \mathrm{H}_{2} \mathrm{O}+7,52 \mathrm{~N}_{2}$, one can determinate the correct amount of $\mathrm{O}_{2}$ in relation of quantity of gas, namely the stoichiometric quantity of $\mathrm{O}_{2}$, which theoretically assures the absence of $\mathrm{CO}$ in the combustion gases. The ratio of the volume of air required to completely combustion a given volume of fuel is 
called stoichiometric air/fuel ratio, (A/F). For methane is $9,52 \mathrm{~m}^{3}{ }_{\text {aire }}{ }^{\prime}$ $\mathrm{m}^{3}{ }_{\mathrm{CH} 4}$. In industrial practice, perfect mixing cannot be achieved. It is actually more cost-effective to ensure complete combustion with the addition of excess air. The excess air ratio can be written in terms of the stoichiometric air/fuel ratio, the combustion air volume flow rate, $Q_{a}$, and fuel volume flow rate, $Q_{f}$.

$$
n=\frac{\dot{Q}_{a}}{\dot{Q}_{f} A / F}
$$

Excess air is that amount beyond theoretical added to ensure complete combustion of the fuel (Baukal, 2001). The stoichiometric equation is modified in equation (3) with $\varepsilon$, the fraction of excess air. In percentage $\% \varepsilon=100(n-1)$.

$$
\mathrm{CH}_{4}+(1+\varepsilon)\left(2 \mathrm{O}_{2}+7,52 \mathrm{~N}_{2}\right) \rightarrow \mathrm{CO}_{2}+2 \mathrm{H}_{2} \mathrm{O}+2 \varepsilon \mathrm{O}_{2}+(1+\mathcal{E}) 7,52 \mathrm{~N}_{2}
$$

The measurement of the combustion efficiency is affected by the fuel supply, excess air level or the oxygen percentage, type of fuel used, combustion air and flue gas temperature. Sensible heat loss is typically the largest loss component in reverberatory furnaces for the high temperatures of the products of combustion. These losses are proportional directly to the combustion gasses volume flow rate and the relation of specific heat $C_{p}$ in function of temperature in the chance internal enthalpy equation:

$$
S H L=\dot{Q}_{c g} \int_{298}^{T_{c g}} C_{p}(T) d T
$$

where $\dot{Q}_{c g}=\dot{Q}_{f}+\dot{Q}_{a}$ and $T_{c g}$ the combustion gasses temperature. It is clear, now, that a direct measure of the percentage of $\mathrm{O}_{2}$, with a gas sensor gives an index of the quality and quantity of the combustion process. Since the percentage can be directly controlled by modulating the air flow by mean of a variable speed fan or damper, suitable control architecture for closed-loop control loop of the quality of the combustion can be realized with the aid of a sensor for measuring the percentage of oxygen. The required 
percentage of oxygen in dry basis at full capacity for used natural gas in the burners of the furnace is between $1,1 \%$ and $3,3 \%$ that corresponding to 5\% and 15\% of excess air (Mullinger, 2008).

\section{NeURAL NETWORK MODEL}

The interconnection of artificial neurons results in an artificial neural network (ANN), its objective is to emulate the function of the human brain or a system and solve the problem. ANN is one of the most applied artificial techniques to model a system based on input-output data. For the task of modeling the reverberatory furnace with a constant flow of fuel in the aluminum heating, the training algorithm used is the back-propagation which computes the gradient; the feedforward network is employed, where the signal flows in a forward direction. A neural model is depicted in Figure 2, where $\boldsymbol{W}$ are the weights, $\mathrm{f}$ the scalar function used in the neurons, $\boldsymbol{x}$ the inputs and $\boldsymbol{y}$ the outputs of the NN, the NN has $\mathrm{n}$ layers and the final layer has to compute the output (Haykin, 2001; Bose, 2002; Liu, et al. 2003).

To represent an unknown function based on the input-output data the ANN has to be trained by the supervised learning process; this selects the appropriate weights distributed in the NN. If the activation function of the neurons in the hidden layer is tanh() and the outputs of this layer are located in $V$, then, the output can be given as in (5), and (6) for the outputs of the network $\boldsymbol{Y}$ (Duda, 2001).

$$
\begin{aligned}
& {\left[\begin{array}{c}
V_{1} \\
\vdots \\
V_{k}
\end{array}\right]=\tanh \left(\left[\begin{array}{ccc}
W_{11} & \ldots & W_{1 j} \\
\vdots & \ldots & \vdots \\
W_{k 1} & \ldots & W_{k j}
\end{array}\right]\left[\begin{array}{c}
x_{1} \\
\vdots \\
x_{j}
\end{array}\right]\right)} \\
& {\left[\begin{array}{c}
Y_{1} \\
\vdots \\
Y_{i}
\end{array}\right]=\tanh \left(\left[\begin{array}{ccc}
W_{11} & \ldots & W_{1 k} \\
\vdots & \ldots & \vdots \\
W_{i 1} & \ldots & W_{i k}
\end{array}\right]\left[\begin{array}{c}
V_{1} \\
\vdots \\
V_{k}
\end{array}\right]\right)}
\end{aligned}
$$




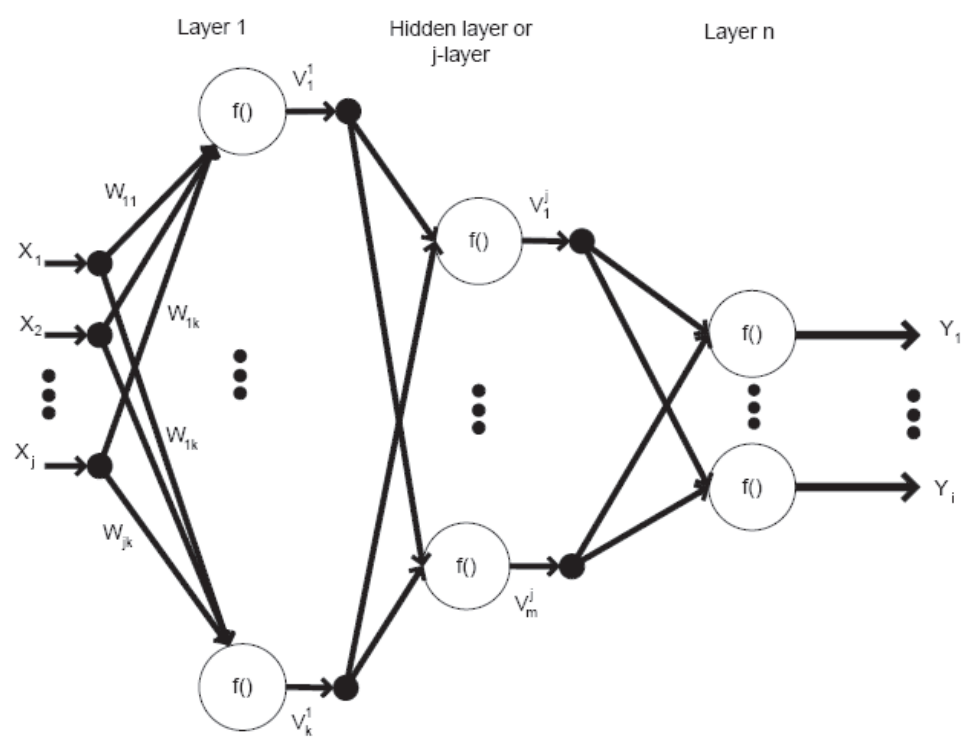

Figure 2. Architecture of the artificial neURAL NETWORK

In order to obtain the best model that represents the system the procedure follows several steps, first the training data set is used, in the second place the model is estimated and the final step employs the validation data set (Jagannathan, 2006).

\section{Genetic algorithm}

The genetic algorithm is a technique used to optimize complex problems; this method employs characteristics of an evolution process, the algorithm uses a population (Ling et al., 2008), the reproduction is made by a change in the population and later the strongest individual survives (Liu, et al. 2003; Ashlock, 2006). To solve the optimization problem the genetic algorithm has to follow the next steps:

1. Choose a codification form (i.e. binary or real). This way makes possible to configure each solution.

2. Computes the fitness function of each configuration. 
3. Select the strongest individuals; those give a fitness function with a very good performance for the problem.

4. Realize the recombination of tow configurations; they are called the parents of the resulting configuration (offspring).

5. With the resulting individuals a mutation is made; this is the way to obtain the new population which is used in the next generation.

The Figure 3 shows the flow of the data in the genetic algorithm, where the stages were described before.

The metric to calculate the distance between the full and final population is the spacing, this metric allows measuring the distribution of the individuals. The expression of the metric is shows in (7).

$$
s=\sqrt{\sum_{i=1}^{n}\left(\bar{d}-d_{i}\right)^{2}}
$$

Where $n$ is the size of the population, $d_{i}=\min _{j}\left|f^{i}-f^{j}\right|$, $i, j=1, \ldots, n, \bar{d}$, is the mean of all $d_{i}$ and $f^{i}$ the fitness function of the $i$ individual. A zero value means that the solutions are equally spaced (Schott, 1995).

\section{Controller}

A simple digital controller of second order is designed; the structure of the controller is presented in (8) (Iserman, 1988); where $\mathrm{u}$ is the control signal, e is the tracking error with its past samples, the aim is to tune the coefficients $q_{i}$ by means of minimizing the cost function defined in (9) that is the mean square error of the tracking problem, with $\mathrm{N}$ the number of samples in a simulation test (Liu et al., 1995; Maiti, 2008). 


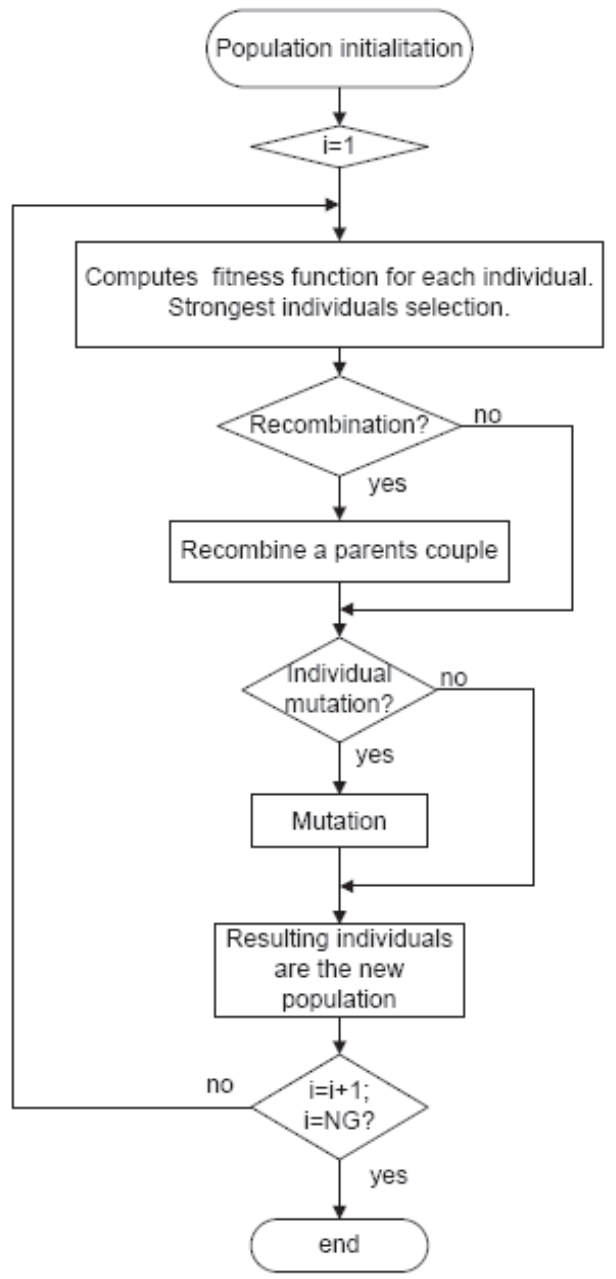

Figure 3. Genetic algorithm

$$
\begin{gathered}
u(k)=u(k-1)+q_{0} e(k)+q_{1} e(k-1)+q_{2} e(k-2) \\
J=\frac{\sum e^{2}}{N}
\end{gathered}
$$




\section{IMPLEMENTATION AND RESULTS}

In order to combine the neural network modeling, the optimization technique and the controller tuning procedure to control the combustion process, the closed loop system is used in Figure 4 (Liu et al., 2005).

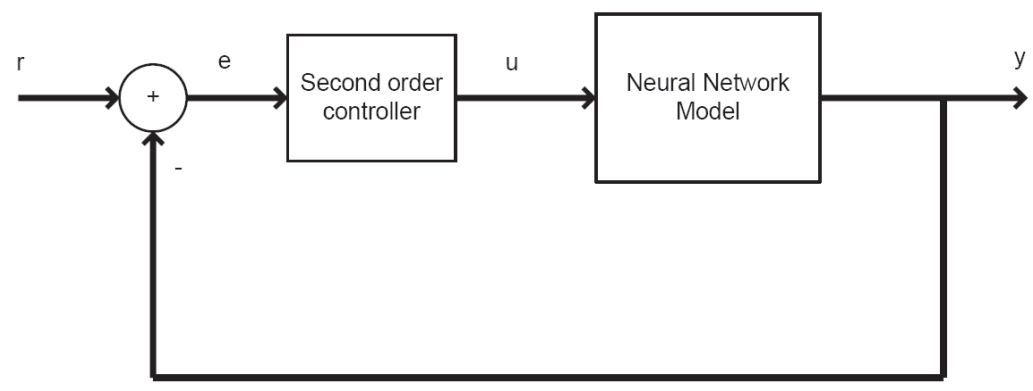

Figure 4. Closed Loop system

The data set employed to estimate the model was obtained from a reverberatory furnace maintaining the thermal power $60 \mathrm{~kW}$ as constant, with variations of air volume flow by variable speed fan and monitoring the oxygen and carbon monoxide percentage in the chimney that assures complete combustion.

In the modeling task, the maximum gas flow or power operation that employs the system was taken into account for the normalization, and assuming that the air flow is proportional to the gas flow to preserve the excess air ratio of the equation (2); the unnormalization procedure uses the gas flow percentage to give the real air flow of the system.

The neural network has the 12 neurons in the input layer, the second layer has 12, the third layer has 8 and the output has 1 neuron, and uses logarithmic sigmoid and hyperbolic tangent sigmoid like activation functions. Figure 5 shows the training process of the neural system in order to model the reverberatory furnace, the training error reaches the order of $0,01 \times 10^{-5}$. 
Model validation is performed with a second data set (Figure 6 ) and its error is shown in Figure 7, the validation analyses the mean square error.

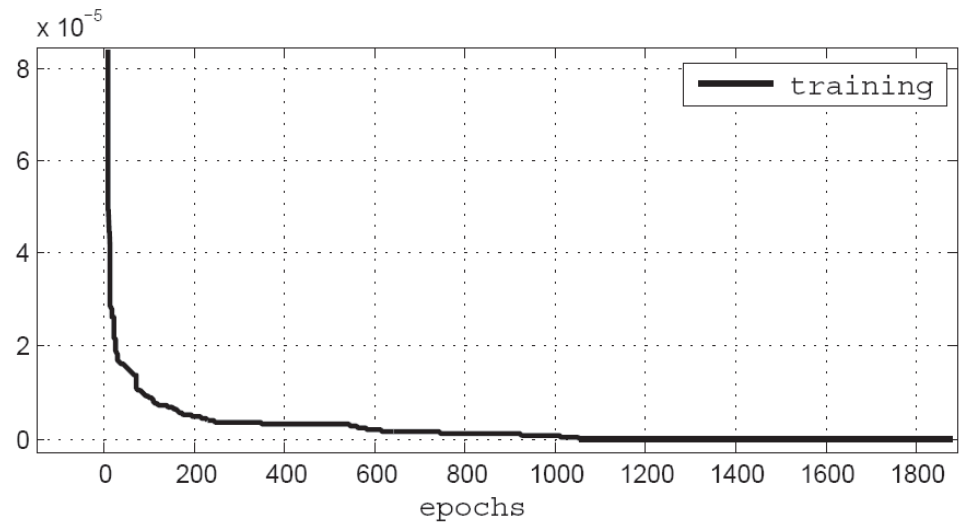

Figure 5. TRAining of THE NEURAL NETWORK SYSTEM

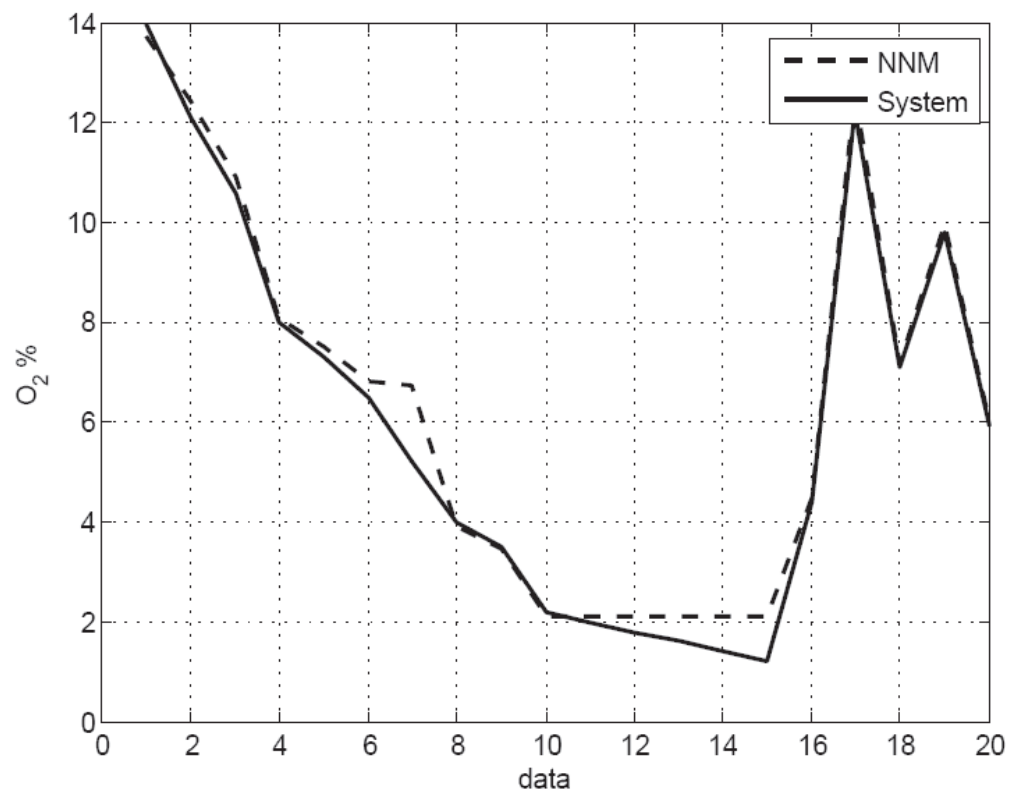

Figure 6. Model Validation SET 


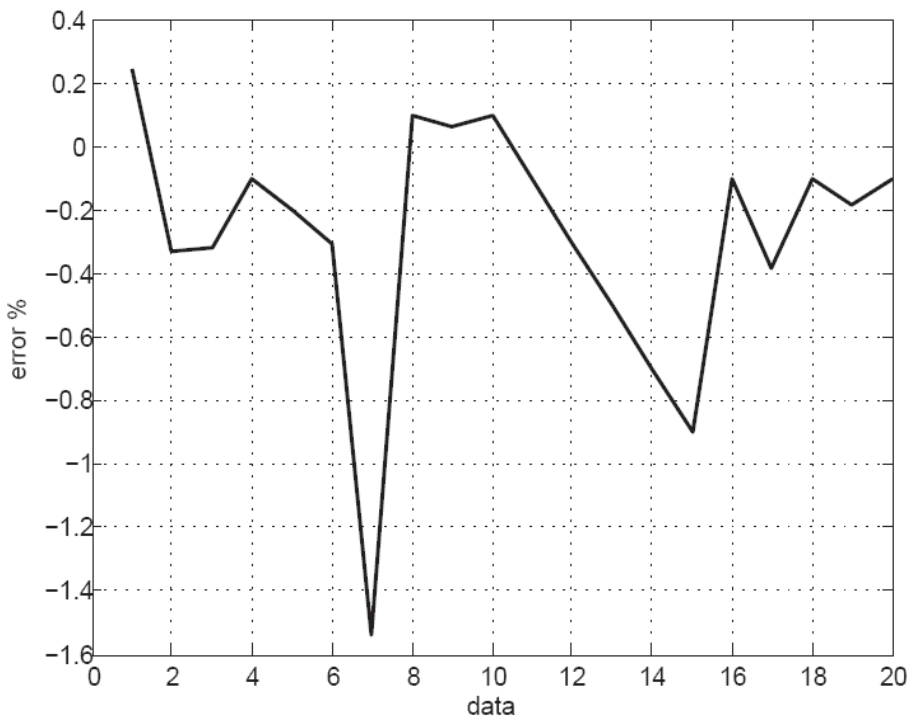

Figure 7. ERROR FOR THE MODEL VALIDATION SET

In order to tune the second order digital controller; the genetic algorithm with the followed characteristics is configured, the codification form is real, the recombination coefficient selected is 0,3 , the mutation coefficient is 0,1 , the population size has 70 individuals, and the number of generations employed is 200. Each individual is formed by the three elements of the regulator; the restrictions to the system design are the minimum flow of the air and the excess air rate.

A metric to observe the distance of the solutions given by the genetic algorithm is employed. The value of the metric in the final population is $s=0,015$, a near distance to zero means that the population is very crowded.

The controller test for an initial condition of the $\mathrm{O}_{2} \%=3,64$ (ci1) and the second test with $O_{2} \%=6,53$ (ci2), the output of both tests for the second order controller designed are shown in Figure 8 , where the system maintains constant around to $\mathrm{O}_{2} \%=2,4$ in order to does not cross the limit of the excess air ratio. If the air flow of the test violates the limit then a simple law restricts the 
air flow to $60 \mathrm{~m}^{3} / \mathrm{h}$ for a system operating at full load condition, this is due to the initial condition of the $\mathrm{O}_{2} \%$ of the system could be very large (Figures 8 and 9).

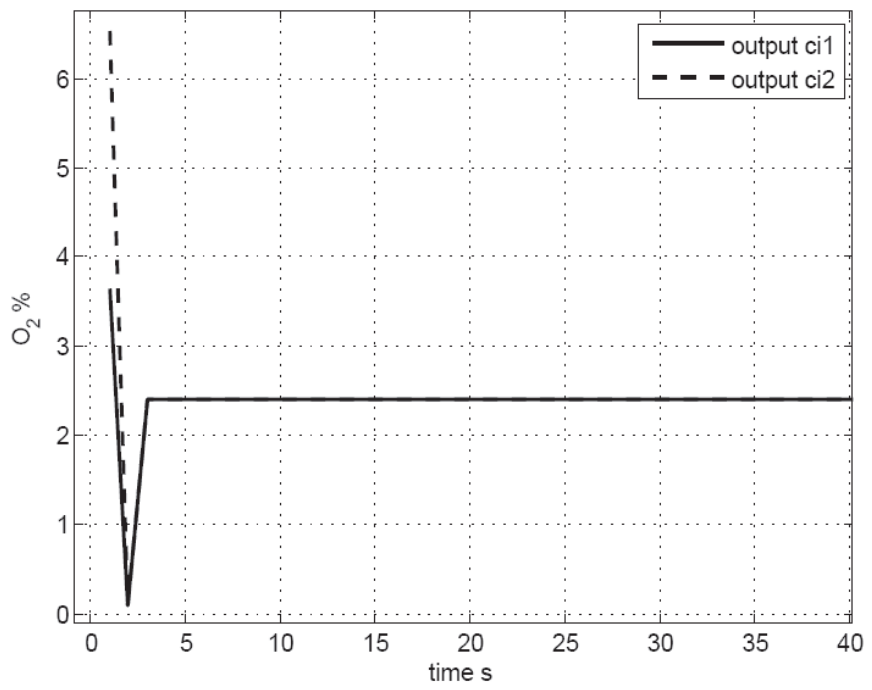

Figure 8. OUtPut of THE CONTROLLED SYSTEM

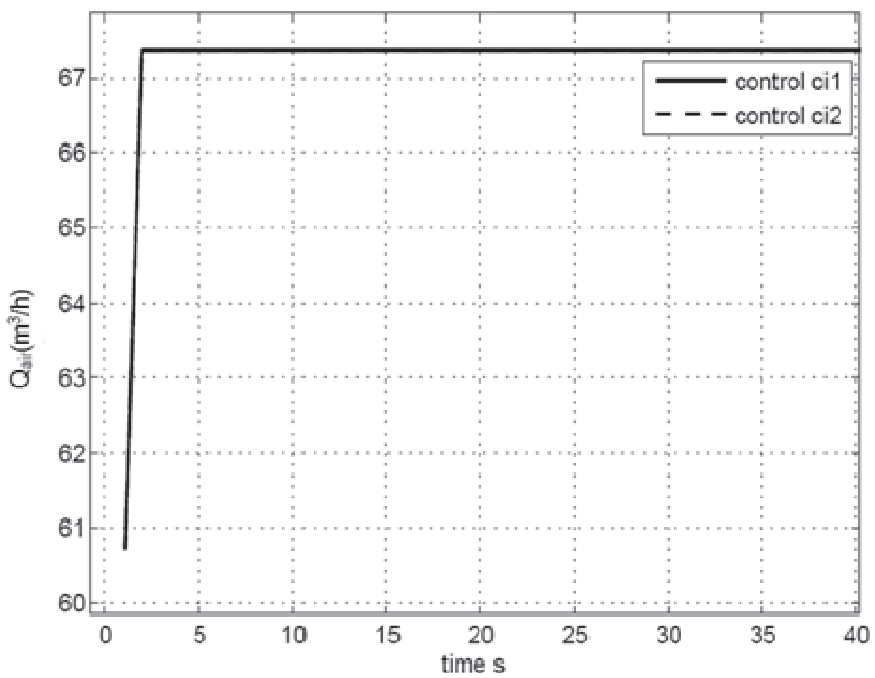

Figure 9. Control signal of the controlled system 
Figure 10 shows the output response of the controller tuned with the genetic algorithm and a Ziegler-Nichols (Z-N) for the initial condition with $O_{2} \%=6,53$ (ci2). Where the optimal control presents a less tracking error and gets the steady state in a minor time.

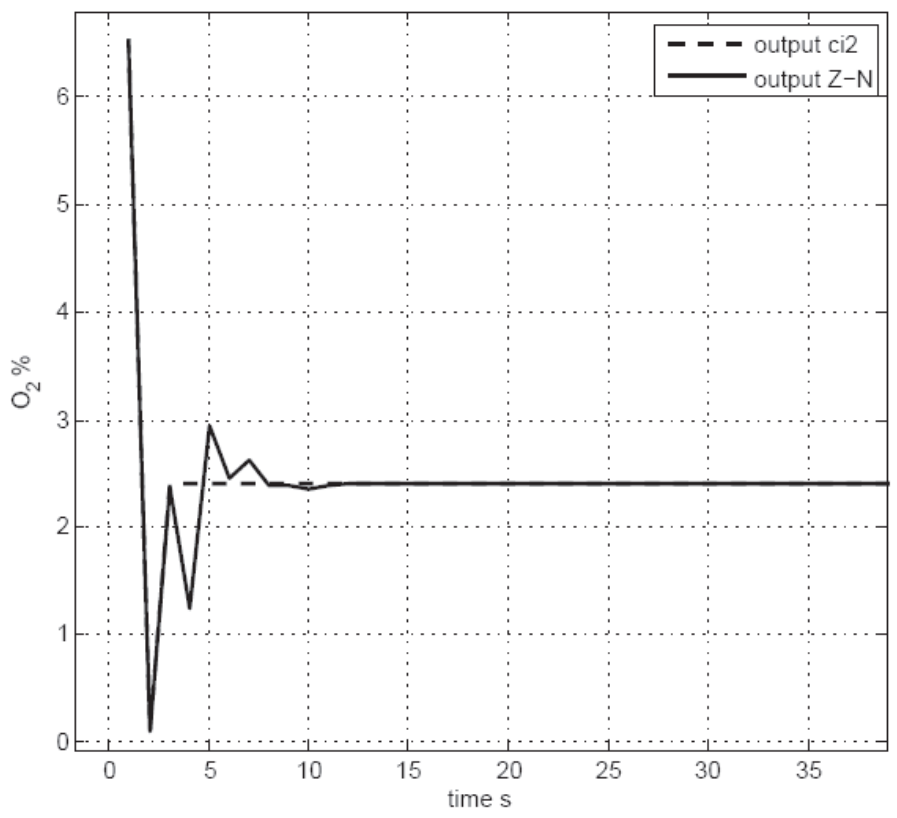

Figure 10. Z-N AND EA SECOND ORDER CONTROLLER

\section{Conclusions}

A methodology to control a reverberatory furnace is presented in this paper; the designed controller employs an evolutionary algorithm to optimize the tracking problem and to find the parameters of a discrete second order regulator that does not cross the system bounds. The application of a neural network to estimate the model of the furnace improves the task of finding a control law for the furnace system. The comparison shows the performances of the Ziegler-Nichols tuning procedure and the method implemented. 
The application of the metric helps in the supervision of the evolutionary algorithm and describes if it drops in a crowded response and the population could be composed by the same individual.

The optimization of the air fuel ratio will reduce the excess air level and improve the combustion efficiency in the furnace system, keeping the value close to $\mathrm{O}_{2} \%=2,4$ in the stack that corresponding to $11 \%$ of excess air. If the system is implemented an operating cost savings will be reached by the reduction of fuel consumption.

\section{References}

Ashlock D. (2006). Evolutionary Computation for Modeling and Optimization. United States of America. Springer.

Baukal C. (2001). The John Zink Combustion Handbook. New York: The John Zink Company. pp 38.

Bose B. (2002). Modern Power Electronics and AC Drives. United States of America: Prentice Hall.

Conte G., Cesaretti M. \& Scaradozzi D. (2006). Combustion control in domestic boilers using an oxygen sensor. 14th Mediterranean Conference on Control and Automation.

Duda P. (2001). Patern Clasification. USA: John Willey and Sons.

Haykin S. (2001). Kalman Filtering and Neural Networks. New York: Jon Wiley and Sons.

Iserman R. (1988). Digital Control Theory, Fundamentals Deterministic Control. Berlin: Springer-Verlag.

Jagannathan S. (2006). Neural Network Control of Nonlinear Discrete-Time Systems. Taylor and Francis.

Ling Q., Wu G., Yang Z. \& Wang Q. (2008). Crowding clustering genetic algorithm for multimodal function optimization. Applied soft Computing. pp 88-95.

Liu T., Ishihara T. \& Inooka H. (1995). Multiobjective control systems design by genetic algorithms. IEEE. SICE 95 Procedings of the 34th SICE annual conference, International session papers. pp 1521-1526.

Liu G., Yang Y. \& Whidborne J. (2003). Multiobjective Optimization and Control. England: Research Studies Press. 
Liu Y., Zhang J. \& Wang S. (2005). Parameter estimation of cutting temperature nonlinear model using PSO algoritm. Journal of Zhejiang University Science. pp 1026-1029.

Maiti D. (2008). Tuning a PID and PI+D Controllers Using the Integral Time Absolute Error Criterion. ICIAFS. IEEE.

McKenna. (1998). Boost the efficiency of your gas - fired aluminun reverberatory furnace. Thermal product solutions. pp 1-4.

Miyayama T., Tanaka S., Miyatake T. \& Umeki T. (1991). A combustion control support expert system for a coal-fired boiler. Electronics, control and instrumentation. Proceedings IECON. International Conference on Volume 2, Issue 28. pp 1513 - 1516.

Mullinger. (2008). Industrial and process furnace principles, desing and operation. Oxford: Elsevier. pp 287-300.

NEDO. (2006). Japanese Technologies for Energy Savings/GHG Emissions Reductions. NEDO. JAPAN, pp 25-27: NEDO.

Santoso H., Nazaruddin Y. \& Muchtadi F. (2006). Boiler performance optimization using fuzzy logic controller. Department of Engineering Physics. Indonesia.

Schott J. (1995). Fault Tolerant Design Single and Multicriteria Genetic Algorithm Optimization. Boston: Masachusetts Institute of Technology.

Trinks W. \& Mawhinney M. (2004). Industrial Furnaces. New Jersey: JOHN WILEY \& SONS, INC. pp 111-113. 